\title{
Spectrophotometric Estimation of Nucleic Acid in Bacterial Suspensions
}

\author{
By P. MITCHELL \\ Department of Biochemistry, University of Cambridge
}

SUMMARY: A method is described for measuring the purine-pyrimidine absorption of Micrococcus pyogenes var. aureus (strain Duncan) (M. pyogenes; Staphylococcus aureus) in intact cell suspensions with the Beckman Model DU spectrophotometer, from which values for the total 'nucleic acid' content of the cells may be obtained. The approximate nature of the method is discussed, but results are presented which show that the values obtained throughout a normal growth of a culture of $M$. pyogenes compare very favourably with the values given by the Schmidt \& Thannhauser (1945) technique. Some observations on Escherichia coli (strain H) suggest that the method may be applicable to organisms other than Micrococcus pyogenes.

In order to facilitate study of the effects of penicillin upon growing $M$. pyogenes (Mitchell, 1949a), a method of estimating total nucleic acid was sought which would be rapid and simple, applicable to small quantities of growing culture or washed suspension and capable of yielding relative values sufficiently accurate to show differences in the pattern of change of the nucleic acid content of normal and treated cells.

The available chemical methods based upon those of Schneider (1945) using pentose estimations, or Schmidt \& Thannhauser (1945) using phosphorus estimations, required more than the amount of material initially available; the application of Caspersson's microspectrophotometric technique to organisms as small as staphylococci, although shown to be possible by Malmgren \& Heden (1947), seemed too uncertain and too laborious to be suitable.

The uniformity of particle size and the known reproducibility of the scattering of white light by bacterial suspensions (Longsworth, 1936; Hershey, 1939) offered promise for the development of a method based upon direct spectrophotometric examination of intact cell suspensions. This paper describes an examination of the scattering and absorption spectra of $M$. pyogenes suspensions which forms the basis of a method of estimating total nucleic acid.

\section{METHODS}

\section{Preparation of suspensions}

$M$. pyogenes var. aureus (Duncan) was grown at $25^{\circ}$ on a medium consisting of a tryptic digest of casein with $1.0 \%$ glucose and $0 \cdot 1 \%$ Marmite. The rotated flask-culture method (Mitchell, 1949b) was employed to give standard and favourable growth conditions.

The reproducibility of the growth curves obtained showed that the physiological state of the cells was more accurately specified by the suspension density than by the age of the culture. The suspension density at harvesting is consequently taken as the index of the physiological condition of the cells used for the photometric studies. 
Escherichia coli $(\mathrm{H})$ was grown at $37^{\circ}$ in 5 ml. lots of the casein digest medium in test tubes.

Washed suspensions of Micrococcus pyogenes were prepared by three rapid centrifugal washings with distilled water. Escherichia coli was washed similarly with three changes of a phosphate buffered saline of composition $\mathrm{Na}^{+}: \mathrm{K}^{+}$: $\mathrm{Mg}^{++}=30: 3: 1, \mathrm{Na}^{+}=0.08 \mathrm{M} ; \mathrm{Cl}^{\prime}: \mathrm{HPO}_{4}{ }^{\prime}: \mathrm{H}_{2} \mathrm{PO}_{4}{ }^{\prime \prime}=6: 1: 1, \mathrm{Cl}^{\prime}=0.06 \mathrm{M}$; ionic strength $0 \cdot 1$.

Dry-weight determinations were made on washed Micrococcus pyogenes suspensions by drying a volume of suspension containing about $20 \mathrm{mg}$. of cells to constant weight at $105^{\circ}$ in an air oven.

All photometric estimations were made in quartz cuvettes holding $3 \mathrm{ml}$. of suspension and giving a light path of $1 \mathrm{~cm}$. Blank determinations were made with the cuvette filled with distilled water (saline for Escherichia coli), before every group of estimations on a new suspension.

\section{Scattering spectrum}

When the transmission of a dilute washed suspension of Micrococcus pyogenes (density at harvesting $\mathbf{2 . 2} \mathrm{mg} . / \mathrm{ml}$.) in distilled water was determined in the Beckman Model DU spectrophotometer for wave-lengths between 2000 and $350 \mathrm{~m} \mu$., the points of Fig. 1 were obtained. The smooth curve which fits the points well from 1000 to $350 \mathrm{~m} \mu$. was drawn by means of the simple inverse law,

$$
\log _{10}\left(I_{0} / I\right)=\text { constant. }
$$

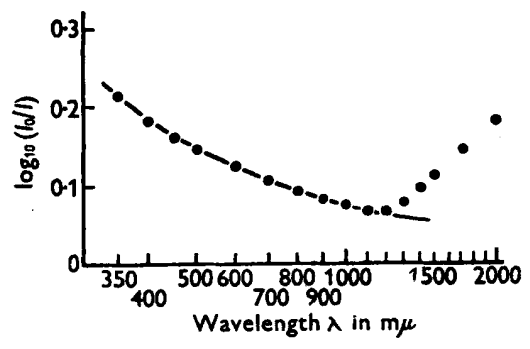

Fig. 1

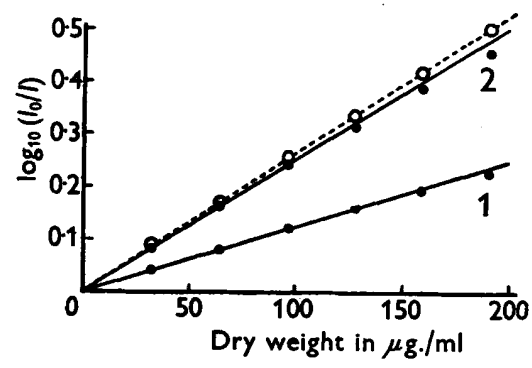

Fig. 2

Fig. 1. Scattering spectrum of $M$. pyogenes suspension of density $84.5 \mu \mathrm{g} . / \mathrm{ml}$. in water. Population density of culture at harvesting $2 \cdot 2 \mathrm{mg} . / \mathrm{ml}$. Full curve, the inverse law.

Fig. 2. Relationship between dry weight of suspension and optical density due to scattering and absorption. Solid points and full lines : optical density due to scattering, 1 at $700 \mathrm{~m} \mu$., 2 at $350 \mathrm{~m} \mu$. Open circles and broken line: computed component of optical density at $260 \mathrm{~m} \mu$. due to absorption.

The optical density plotted against suspension density for wave-lengths of 700 and $350 \mathrm{~m} \mu$. gave the solid points of Fig. 2. It will be observed that for values of suspension density $(m)$, up to $100 \mu \mathrm{g} . / \mathrm{ml} ., \log _{10}\left(I_{0} / I\right)$ is proportional to $m$; so that the scattering spectrum between 1000 and $350 \mathrm{~m} \mu$. can be represented by the relationship

$$
\log _{10}\left(I_{0} / I\right)=k m / \lambda
$$

where $k$ is 0.90 if $\lambda$ is expressed in $\mathrm{m} \mu$. and $m$ in $\mu \mathrm{g} . / \mathrm{ml}$. 
The constituents of the cells absorb very little light of wave-lengths between 2000 and $350 \mathrm{~m} \mu$., and we may consider the plot of the optical density against wave-length over this range to represent the scattering spectrum of the cells. It must, however, be borne in mind that transmission spectra due to scattering are dependent upon the aperture of the light-sensitive cell of the photometer, because of collection of part of the forward-scattered light with the transmitted part of the incident beam. As a result, unless special precautions are taken, scattering spectra are to some extent characteristic of the photometer used to measure them.

The minimum in the scattering spectrum of suspensions of $M$. pyogenes at $1200 \mathrm{~m} \mu$. and the sharp rise towards $2000 \mathrm{~m} \mu$. in the near infra-red were not expected, and it was at first thought that they might be due to light absorption. This possibility was eliminated when it was found that the scattering spectra of

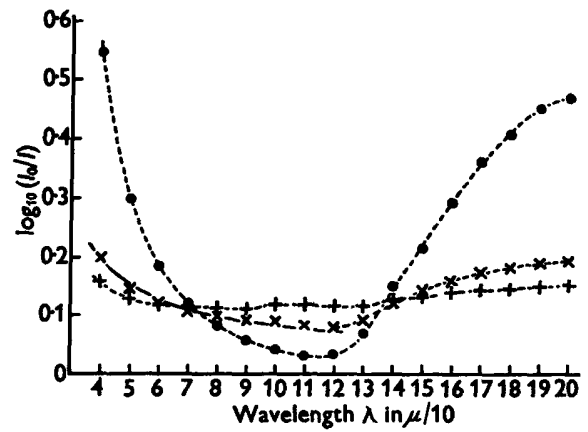

Fig. 3

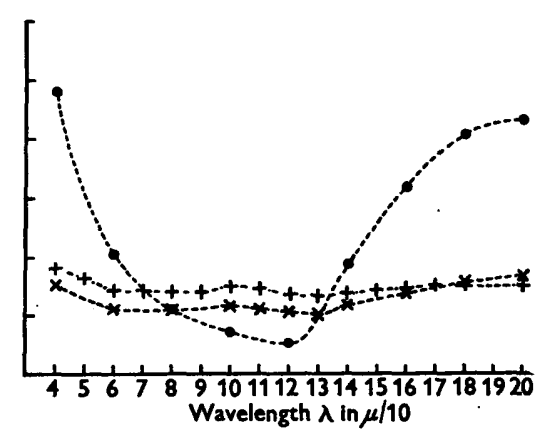

Fig. 4

Fig. 8. Scattering spectra of oleic acid particles in water. Solid points (-- - - - -), submicroscopic particles; oblique crosses $(--\times-\times--)$, particles $0 \cdot 7-2 \mu$. in diameter; erect crosses $(\cdots+\cdots+--)$, particles $4 \mu$. in diameter; full line, the inverse law. Concentrations arbitrary.

Fig. 4. Scattering spectra of glass particles. Solid points (- - - - - - ), particles of diameter $<0.5 \mu$. in water; erect $(--+\cdots+--)$ and oblique $(--x-\cdots \times--)$ crosses, particles of diameter $5 \mu$. in water and medicinal paraffin respectively. Concentrations arbitrary.

oleic acid particles of various sizes in water (Fig. 3) and glass particles in water and in medicinal paraffin (Fig. 4) were of the same general form. In all cases there was a minimum near $1200 \mathrm{~m} \mu$., but the rise in the scattering power of the suspension on either side of the minimum was steeper the smaller the particles. Only for the oleic acid suspension, which was found by microscopic examination to consist of particles between 0.7 and $2 \mu$. in diameter, did the scattering spectrum approximate closely to the inverse law (full curve). This suggested that the changes in cell diameter which occur during growth might be accompanied by changes in the scattering characteristics.

The scattering spectrum of a suspension of cells harvested in the early part of the log phase of growth (density at harvesting $0.3 \mathrm{mg} . / \mathrm{ml}$.) was found to approximate to the inverse law as closely as the suspension of Fig. 1, but the scattering coefficient $k$ was $5 \%$ lower than for the older cells. The value of 
$k$ at $350 \mathrm{~m} \mu .\left(k_{350}\right)$ and the ratio of the values of $k$ at 350 and $700 \mathrm{~m} \mu .\left(k_{350} / k_{700}\right)$ taken at intervals throughout a normal growth are set out in Table 1 . The figures indicated that in the late lag phase, the scattering spectra were flatter, while at the approach to the stationary phase they were steeper than the inverse law. This is in conformity with the observation that the cells were larger in the earlier phases of the growth of the culture. The theoretical value of the scattering power at $350 \mathrm{~m} \mu$., calculated from that at $700 \mathrm{~m} \mu$. by means of the inverse law, gives a deviation from the experimental value not greater than $11 \%$.

Table 1. Slope of scattering spectrum of Micrococcus pyogenes during growth of culture

\begin{tabular}{|c|c|c|c|}
\hline $\begin{array}{l}\text { Time } \\
\text { (hr.) }\end{array}$ & $\begin{array}{c}\text { Growth } \\
(\mu \mathrm{g} . / \mathrm{ml} .)\end{array}$ & $k_{350}$ & $k_{350} / k_{700}$ \\
\hline 0 & 51 & 0.93 & $0 \cdot 89$ \\
\hline $\mathbf{2 \cdot 5}$ & 72 & 0.97 & $0 \cdot 89$ \\
\hline $5 \cdot 5$ & 214 & 0.94 & 0.94 \\
\hline $7 \cdot 5$ & 475 & 0.94 & 0.99 \\
\hline $10 \cdot 5$ & 1220 & $0 \cdot 85$ & $1 \cdot 03$ \\
\hline $13 \cdot 5$ & 2480 & 0.84 & $1 \cdot 08$ \\
\hline 16.5 & $\mathbf{3 6 6 0}$ & 0.92 & 1.06 \\
\hline $21 \cdot 5$ & 3800 & 0.97 & 1.05 \\
\hline
\end{tabular}

\section{Absorption spectrum}

On extending the spectrophotometric measurements into the ultra-violet, it was found that the cells not only scattered the incident light but also absorbed it. Fig. 5 shows that there are two disturbances, one at $260 \mathrm{~m} \mu$. and the other at about $280 \mathrm{~m} \mu$., corresponding to the ultra-violet absorption maxima of purines and pyrimidines and of aromatic amino-acids. In order to confirm that the deviations from the scattering spectrum indicated by extrapolation of the inverse law were due to absorption and not to an anomalous scattering phenomenon, the effect of changing the refractive index of the suspension medium was determined; for it would be expected that, other things being equal, a change of refractive index difference between the suspended particles and suspension medium should affect the scattering power of the suspension without altering its light absorption. The transmission spectra of the same batch of cells were determined in $\mathbf{4 0} \%$ aqueous and pure glycerol at the same suspension density as was employed for the measurements in water. The results plotted in Fig. 5 show that the scattering was reduced to about $1 / 5$ in pure glycerol, while it had an intermediate value in $40 \%$ glycerol. In all three cases the simple inverse law gives quite a good fit for the scattering spectrum between 1000 and $350 \mathrm{~m} \mu$. On the other hand, the increment of $\log _{10}\left(I_{0} / I\right)$ at $260 \mathrm{~m} \mu$. was nearly independent of the glycerol concentration (0.298 in water, 0.308 in $40 \%$ glycerol, $\mathbf{0 . 2 9 0}$ in absolute glycerol). It thus appeared justifiable to extrapolate the inverse scattering law from the visible region, where the cells do not absorb, to the near ultra-violet, where absorption did occur. 
We now proceed by assuming that the Beer-Lambert law applies to the 'nucleic acid' in the cell suspension as if it were in homogeneous solution in the same volume, and that the absorption and scattering spectra contribute additively to the transmission spectrum. On this basis, the increment of $\log _{10}\left(I_{0} / I\right)$ at $260 \mathrm{~m} \mu$. above the value given by the inverse scattering spectrum

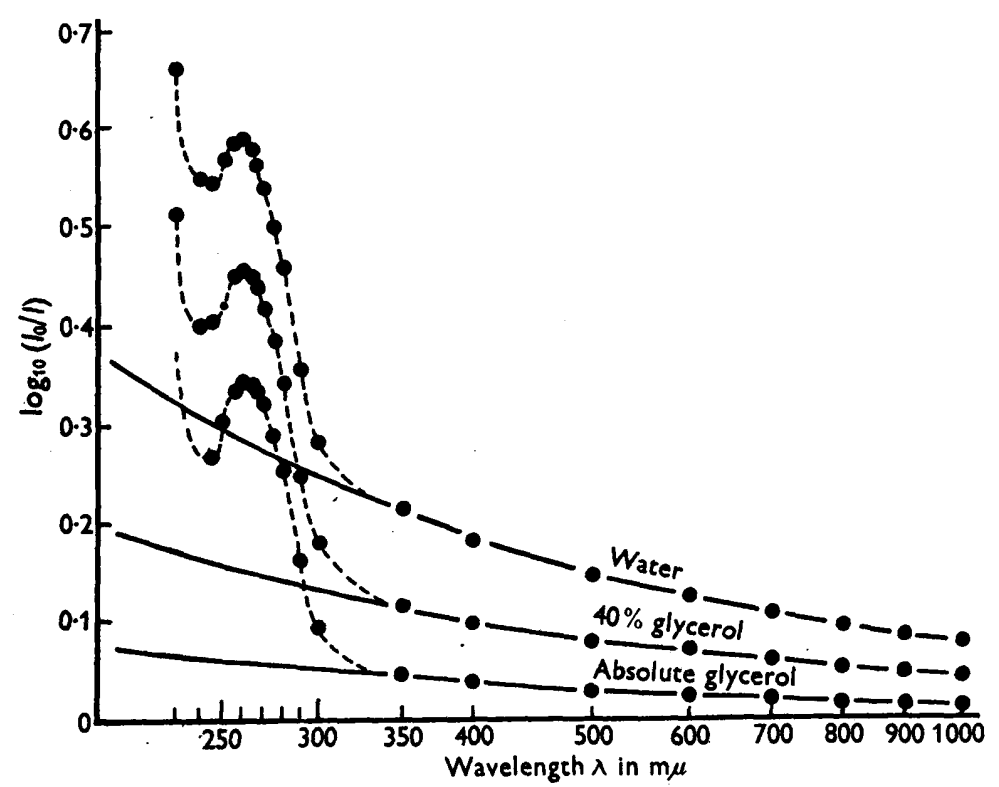

Fig. 5. Effect of refractive index of the medium upon the scattering + absorption spectrum of $M$. pyogenes. Suspension density $84.5 \mu \mathrm{g} . / \mathrm{ml}$. in all cases. Population density at harvesting $2 \cdot 2 \mathrm{mg} / \mathrm{ml}$. Full lines, the inverse law.

extrapolated from $850 \mathrm{~m} \mu$. may be taken to represent the 'nucleic acid' absorption. In other words, the percentage by weight of 'nucleic acid' in the cells can be arrived at by means of only two measurements, namely of $\log _{10}\left(I_{0} / I\right)$ at 350 and at $260 \mathrm{~m} \mu$. The dry weight is determined from $\log _{10}\left(I_{0} / I\right)$ at $850 \mathrm{~m} \mu$. and the value of $k_{350}$; the scattering contribution to the optical density at $260 \mathrm{~m} \mu$. is taken as $350 / 260$ times $\log _{10}\left(I_{0} / I\right)$ at $350 \mathrm{~m} \mu$., and this value subtracted from the observed value of $\log _{10}\left(I_{0} / I\right)$ at $260 \mathrm{~m} \mu$. to give the absorption due to 'nucleic acid'. Accepting the value of 200 for the percentage decadic absorption coefficient $\left(=(1 / c d) \log _{10}\left(I_{0} / I\right)\right.$, where $d=$ light path in $\mathrm{cm}$. and $c=$ concentration in $\%(w / v))$ given by Malmgren \& Heden (1947), the cells of Fig. 5 were found to contain $18 \%$ by weight of 'nucleic acid'.

A plot of suspension density against apparent nucleic acid absorption (open circles of Fig. 2) gave a straight-line relationship over a broader range than held for the plot of optical density against suspension density. Consequently, when estimations are done on suspensions of greater density than $100 \mu \mathrm{g} . / \mathrm{ml}$., the percentage by weight of 'nucleic acid' comes out too high unless $k$ is appropriately adjusted to correct for the non-linearity of the relationship between optical density and dry weight. The necessity for such corrections can 
readily be avoided by using suspensions of densities between 30 and $100 \mu \mathrm{g} . / \mathrm{ml}$. for making the estimations.

While it is obvious that several of the assumptions which it has been necessary to make may be only partially justified, and the results consequently in error as absolute measurements by quite a wide margin, we should expect the comparative measurements to be less inaccurate. Fig. 6 shows duplicate experiments in which the percentage by weight of 'nucleic acid' ( $\%$ NA) in $M$. pyogenes has been estimated throughout a normal growth period (open and closed circles). The complete cycle of $\%$ NA change is exhibited, and although

Table 2. The evaluation of \% NA during growth of Micrococcus aureus and comparison with phosphorus method of Schmidt \& Thannhauser

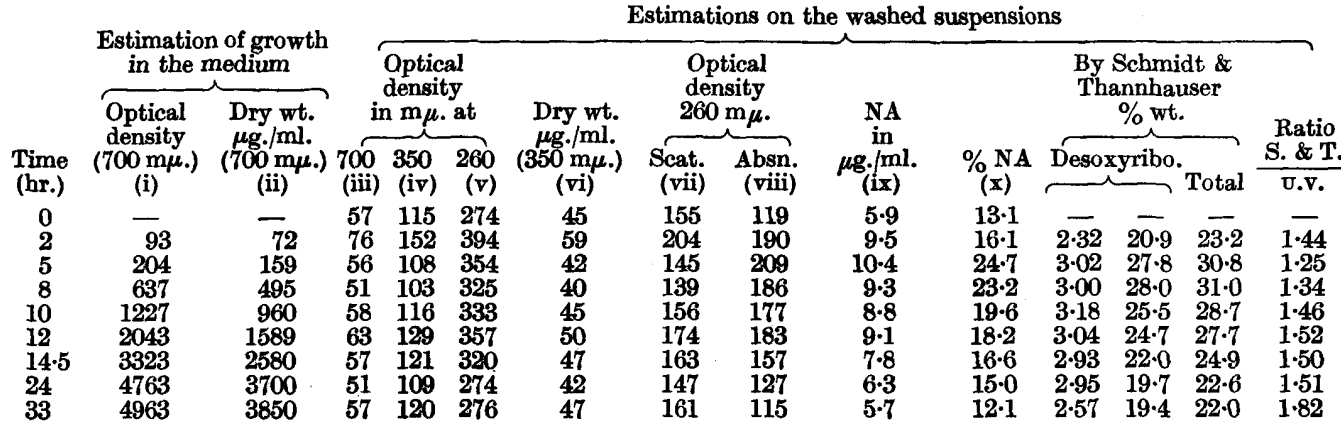

(i) = Optical density $\left(\log _{10} \frac{I_{0}}{I} \times 1000\right)$ at $700 \mathrm{~m} \mu$, of the culture.

(ii) $=$ (i) $\times \frac{700}{0.9} \times \frac{1}{1000}$.

(iii, iv, v) = Optical densities of washed suspensions in water.

(vi) $=$ (iv) $\times \frac{350}{0.9} \times \frac{1}{1000} . \quad$ (vii) $=($ iv $) \times \frac{350}{260} . \quad($ viii $)=(v)-($ vii $)$.

(ix) $=$ (viii) $\times \frac{1}{20} . \quad(\mathrm{x})=\frac{(\mathrm{ix})}{(\mathrm{vi})} \times 100$.

$\log _{9} m$ is obtained from (ii) and $k_{250} / k_{700}$ from (iv)/(v).

the lag phase apparently differed by over an hour in the two experiments, the course of the changes in $\%$ NA was very nearly coincident. The figures for one of these experiments are set out in Table 2 to illustrate the method of calculation. The values of the ribonucleic and desoxyribonucleic acid contents of the same samples of cells are shown for comparison. These were kindly obtained by Jennifer Moyle, using an adaptation of the Schmidt \& Thannhauser phosphorus method (Stephenson \& Moyle, 1949). The latter values for the ribonucleic acid and total nucleic acid contents of the cells are also plotted in Fig. 6 (crosses corresponding to open circles). In these experiments, the inoculum was prepared by growing one Roux bottle sown with $5 \mathrm{ml}$. of $M$. pyogenes (suspension density in medium $2 \mathrm{mg}$. $/ \mathrm{ml}$.) for $48 \mathrm{hr}$. at $25^{\circ}$, when the density reached about $0.85 \mathrm{mg} . / \mathrm{ml}$. Two litres of medium, stirred and aerated in a $5 \mathrm{l}$. rotated flask, was sown with $100 \mathrm{ml}$. of the inoculum and samples subsequently taken, beginning with a volume of $200 \mathrm{ml}$. and diminishing 
as the dry weight of the culture increased, so as to keep the dry weight of each sample at about $30 \mathrm{mg}$. From each sample, $5 \mathrm{ml}$. were taken immediately for estimation of $\log _{10}\left(I_{0} / I\right)$ at $700 \mathrm{~m} \mu$., where the small absorption of the medium was readily compensated by a blank estimation, and the dry weight calculated on the basis of $k=0.90$. The remainder was centrifugally washed three times in distilled water and made up to a volume of just over $11 \mathrm{ml}$. Of this, $1 \mathrm{ml}$. was

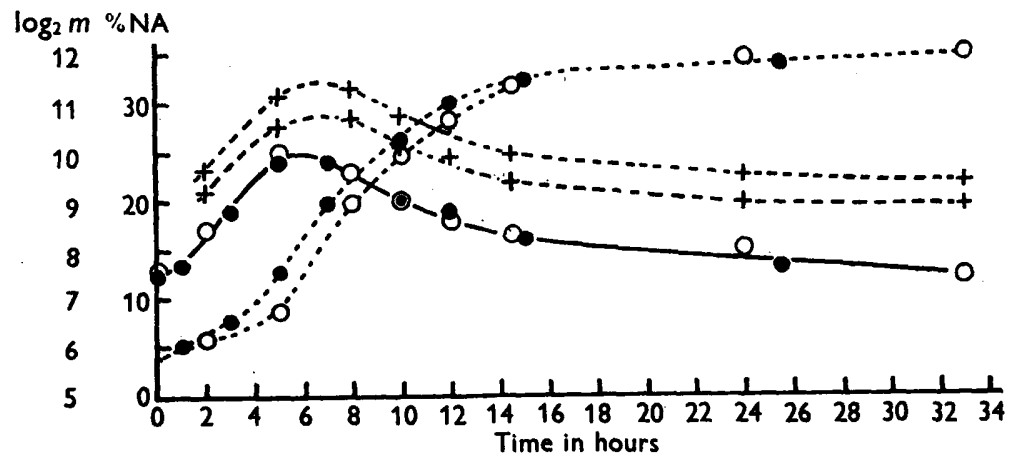

Fig. 6. The percentage by weight of 'nucleic acid' estimated throughout a normal growth of M. pyogenes. Open (--O--O--) and closed (-- $\left.-O_{--}\right)$circles on broken (-....-) lines, $\log _{2}(d r y$ weight in $\mu \mathrm{g} . / \mathrm{ml}$.) indicating phase of growth, duplicate experiments; open (-O-O - ) and closed (- - - - - - ) circles on full ( $-(-)$ line, corresponding percentages by weight of 'nucleic acid' in the cells estimated by present method. Erect (--+--+--) crosses on broken lines, estimation of ribonucleic and total nucleic acid by the method of Schmidt \& Thannhauser (1945) corresponding to open circles. Open circles $(O \bigcirc O)$ and crosses $(t++)$ correspond to figures of Table 2.

suitably diluted (usually $1 / 100$ ), and used for the spectrophotometric estimations, while $10 \mathrm{ml}$. were pipetted into $2 \mathrm{ml}$. of $30 \%$ trichloroacetic acid and reserved for chemical estimation.

The absolute values of the percentage by weight of 'nucleic acid' obtained by the present method are about $30 \%$ lower than those given by the Schmidt \& Thannhauser phosphorus technique. The ratio of the two values, however, shows a standard variation of only $10 \%$.

A closer examination now in progress, of the results given by the Schmidt \& Thannhauser method, has shown that the phosphate values of the 'ribonucleic acid fraction' are too high to be accounted for on the basis of a tetranucleotide structure. A typical sample of $M$. pyogenes (density at harvesting from Roux bottle, $1 \mathrm{mg} . / \mathrm{ml}$.) gave the values of Table 3 , based upon phosphorus and ultra-violet absorption estimations on the fractions. The absorption measurements on the extracts agreed well with the value of $18.5 \%$ for the $\%$ NA found on the cell suspension. It will be noticed that this value includes the acid-soluble fraction. Although the acid-soluble purine-pyrimidine fraction is omitted in the estimation of total nucleic acid by the Schmidt \& Thannhauser method, the figure for the total 'nucleic acid' obtained either on the intact suspension or on the fractions by the ultra-violet absorption measurements was $\mathbf{3 0} \%$ lower than that obtained by the phosphorus estimations. The absolute 
Table 3. Comparison of phosphorus and ultra-violet estimation of 'nuclenc acid' in Schmidt \& Thannhauser fractions of Micrococcus aureus

$$
\begin{gathered}
\text { Fractions by } \\
\text { Schmidt \& } \\
\text { Thannhauser } \\
\text { (1945) }
\end{gathered}
$$

Acid soluble

Ribonucleic acid

\begin{tabular}{|c|c|c|}
\hline $\begin{array}{l}\text { By absorption } \\
\text { at } 260 \mathrm{~m} \mu \text {. } \\
\text { (coeff. } 200 \text { ) }\end{array}$ & $\begin{array}{c}\text { By } \\
\text { phosphorus } \\
\text { content }\end{array}$ & $\begin{array}{l}\text { Direct on } \\
\text { cell } \\
\text { suspension }\end{array}$ \\
\hline $\mathbf{2 \cdot 7}$ & - & - \\
\hline $\begin{array}{r}11 \cdot 4 \\
4 \cdot 0\end{array}$ & $\begin{array}{r}21 \cdot 3 \\
4 \cdot 4\end{array}$ & - \\
\hline $18 \cdot 1$ & $35 \cdot 7$ & $18 \cdot 5$ \\
\hline
\end{tabular}

Desoxyribonucleic acid

Total
Percentage by weight of 'nucleic acid'

discrepancies between the \% NA values and the values for the percentage of total nucleic acid given by the Schmidt \& Thannhauser technique thus appear to be due rather to inaccuracies in the phosphorus method than in the present ultra-violet absorption method. The absorption coefficient of 200 assumed for the 'nucleic acid' is probably a lower limit. When a value near the probable upper limit of 250 is used, the \% NA values are lowered by $20 \%$.

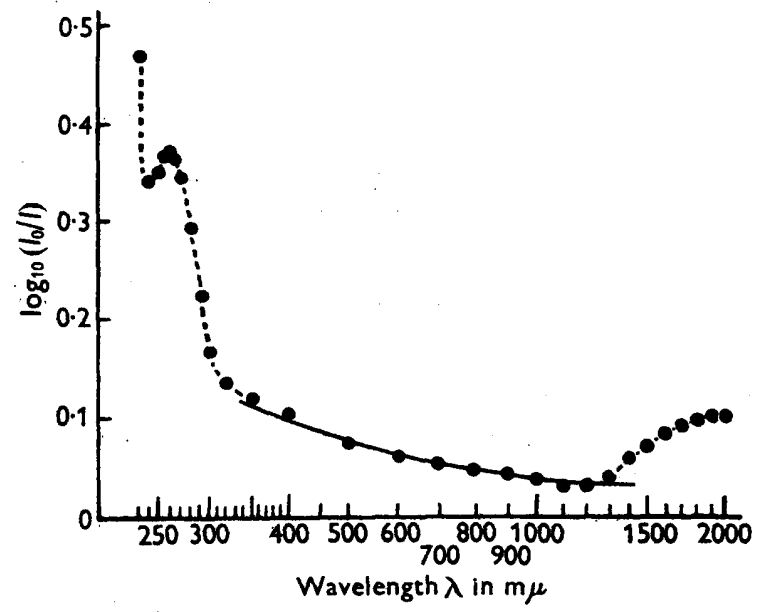

Fig. 7. Absorption and scattering spectrum of Esch. coli (strain $\mathbf{H}$ ) in phosphate buffered saline, suspension density $46 \mu \mathrm{g} . / \mathrm{ml}$. Full line, the inverse law.

The transmission spectrum of a washed suspension of Escherichia coli (strain $\mathbf{H}$ ) in phosphate buffered saline is shown in Fig. 7. As in the case of the micrococcus, the scattering spectrum between 1000 and $350 \mathrm{~m} \mu$. approximated closely to the simple inverse law. The estimation of $\%$ NA of the cells, harvested in the late log phase of growth, gave $22.8 \%$ when the same method of computation was used as for the micrococcus.

\section{DISCUSSION}

The photometric estimation of substances inside cells, whether by microscopic observations upon individual cells or by spectrophotometric examination of cell suspensions, depends upon certain assumptions of questionable validity. 
It is assumed in the method described in this paper that the Beer-Lambert law is applicable to the 'nucleic acid' of the cell suspension as if it were in homogeneous solution in the same volume. The 'nucleic acid', of course, includes all the substances showing the purine-pyrimidine absorption at $260 \mathrm{~m} \mu$., and we have referred to it as 'nucleic acid' or NA in order to avoid confusion. The part of the NA which is uniformly distributed in the cells may reasonably be expected to obey the Beer-Lambert law, but the applicability of the law to the variable proportion which is present in the cells as granules is very uncertain. Moreover, the choice of the absorption coefficient of the NA, as present in the cells, is difficult, because the NA is a complex mixture, the concentration of some components of which is high, and there may be some degree of orientation. Malmgren \& Heden's value of 200 for the percentage decadic absorption coefficient has been accepted mainly on the ground that it is a good round number. Under the circumstances, it would not be consistent to attempt to correct for the small absorption of other substances such as aromatic aminoacids at $260 \mathrm{~m} \mu$.

It is further assumed that the absorption and scattering spectra contribute additively to the transmission spectrum of the suspension; and that the scattering contribution in the near ultra-violet, where the cells absorb strongly, can be obtained by extrapolation of the inverse scattering law from the visible region where there is little light absorption. These two assumptions are supported by the observations that a change of refractive index of the suspension medium which causes a fivefold change in the scattering coefficient of Micrococcus pyogenes has little or no effect either upon the form of the scattering spectrum or upon the estimated NA absorption; and that there is a linear relationship between the suspension density and the estimated NA concentration over a broad range. No other direct evidence has been obtained in support of the basic assumptions, and no attempt will be made to argue against their doubtful validity.

The occurrence of a minimum in the scattering spectrum of the suspension of $M$. pyogenes is in agreement with the theoretical considerations of LaMer (1943) on smokes, and with the experimental observations of Bailey (1946) on suspensions in liquids. For $M$. pyogenes harvested during the major part of the log phase of growth, the value of the optical density of the washed suspension between 1000 and $850 \mathrm{~m} \mu$. is inversely proportional to the wave-length. Significant deviations occur, however, when the cells are harvested at phases of growth when they are larger or smaller than the logarithmically growing cells. At the phases of growth where the cells are larger the spectra are flatter, while, when they are smaller the spectra are steeper, in conformity with observations on oleic acid and glass suspensions of different particle sizes.

During a normal growth cycle, the value of $k_{250} / k_{700}$ has been found to be equal to $1 \pm 11 \%$, so that the error introduced into the determination of the scattering contribution to the optical density at $260 \mathrm{~m} \mu$. from the value at $350 \mathrm{~m} \mu$., on the assumption that $k_{230}=k_{250}$, may be considered to be $\pm 5 \%$; and since the scattering and absorption contributions to $\log _{10}\left(I_{0} / I\right)$ at $260 \mathrm{~m} \mu$. are approximately equal, the error introduced into the estimation of $\% \mathrm{NA}$ is 
also $\pm 5 \%$. No correction has been applied for this error, but it should be borne in mind that a correction may become necessary if the physiological conditions of the cells induce abnormal size variations, recognized by abnormal deviations of $k_{350} / k_{700}$ from unity. Indeed, the measurement of the slope of the scattering spectrum might form the basis of a quantitative method of measuring changes of mean cell diameter.

In addition to changes in $k_{350} / k_{700}$ during growth, there are variations in the absolute value of $k_{350}$ which are probably caused in part by factors other than changes in cell size. The value of $k_{350}$ shows a drop of about $10 \%$ at the approach to the stationary phase of growth and later a rise to the initial value. This variation introduces a $10 \%$ error in the value of $\% \mathrm{NA}$ if $k_{350}$ is assumed to remain constant. The error may be avoided by determining $k_{350}$ gravimetrically on the washed suspensions used for the photometric measurements, a procedure which becomes essential if the scattering characteristics of the cells are suspected of being abnormal. Attention should, perhaps, be drawn to the fact that turbidimetric methods of estimating dry weight are generally liable to errors of $10 \%$ or more unless calibrations are made with cells in corresponding physiological states (Longsworth, 1936; Hershey, 1939).

In view of the nature of several of the assumptions involved in the evaluation of $\% \mathrm{NA}$, it was not surprising to find that the absolute values fell about $30 \%$ short of those obtained by the Schmidt \& Thannhauser phosphorus method. The subsequent finding that most of this discrepancy appears to be due to the erroneously high values of the phosphorus method was quite unexpected, and is at present under investigation. The ratio of the two values, however, shows a standard variation of only $10 \%$ under the normal range of physiological conditions obtaining during the growth of the culture.

The single experiment on Escherichia coli (strain H), harvested towards the end of the log phase, indicates that the same method of measuring \% NA may be applied as has been used for $M$. pyogenes. The \% NA in Esch. coli measured in this way is nearly the same as in the micrococcus at the same phase of growth. It is suggested that the present method of estimating total 'nucleic acid' may be of general applicability when the necessary exploratory data have been obtained.

I am indebted to Dr Gale and the members of the Medical Research Council's Unit for Chemical Microbiology at Cambridge for valuable help and criticism, and to the Medical Research Council for a personal grant.

\section{REFERENCES}

Batley, E. D. (1946). Particle size by spectral transmission. Industr. Engng Chem. (Analyt. ed.), 18, 365.

Hershey, A. D. (1939). Factors limiting bacterial growth. 4. The age of the parent culture and the rate of growth of transplants of Escherichia coli. J. Bact. 37, 285.

LAMEr, V. K. (1943). Progress report on 'Verification of mie theory-calculations and measurements of light scattering by dielectric spherical particles'. Report OSRD, no. 1857.

Longsworth, L. G. (1986). The estimation of bacterial populations with the aid of a photoelectric densitometer. J. Bact. 32, 307. 
Matmgren, B. \& Heden, C. (1947). Studies of the nucleotide metabolism of bacteria. 1. Ultraviolet microspectrography as an aid in the study of the nucleotide content of bacteria. Acta Path. microbiol. Scand. 24, 417.

Mrtcheld, P. (1949a). Some observations on the mode of action of penicillin. Nature, Lond., 164, 259.

Mitcheld, P. (1949b). A new technique for stirred aerated culture. Nature, Lond., $164,846$.

Schmidt, G. \& Thannhauser, S. J. (1945). A method for the determination of desoxyribonucleic acid, ribonucleic acid, and phosphoproteins in animal tissues. J. biol. Chem. 161, 83.

Schneider, W. C. (1945). Phosphorus compounds in animal tissues. 1. Extraction and estimation of desoxypentose nucleic acid and of pentose nucleic acid. J. biol. Chem. 161, 293.

Stephenson, M. \& MoYLE, J. M. (1949). Nucleic acid metabolism of Escherichia coli. Biochem. J. 45, vii.

(Received 17 December 1949) 